\title{
Sharing knowledge
}

\section{Neuroscience and the circulation of medical knowledge}

\author{
Åsa Alftberg
}

Knowledge has long been studied in the social sciences and the humanities with focus on its production and construction. For example, Science and technology studies (STS) has explored and revealed the making of scientific knowledge in particular contexts, often the lab, and the ordering of science and knowledge has been linked to the ordering of society (Jasanoff 2004). As Sheila Jasanoff (2004) has stated, doing science is related to power and merges into doing politics. The making of science is a history of knowledge dependent on power and culture. In Jasanoff's words, science and society are co-produced, each underwriting the other's existence.

A complementary but different approach which has gained traction recently is the circulation of knowledge. The concept directs attention towards 'how knowledge moves, and how it is continuously moulded in the process' (Östling et al. 2018, 17). For Johan Östling and his colleagues, inspired by work by the likes of Philipp Sarasin and Andreas Kilcher, the circulation of knowledge is characterized by the mediality and materiality of knowledge (18). Knowledge is embedded in social contexts and for the most part mediated through material objects. It is always formed by power relations and cultural processes, which implies that the accessibility of knowledge is dependent on its specific position, time, and place, 
and differs between societies. As it circulates, knowledge-like notions, things, people-often transforms (Markovits et al. 2006). The circulation of knowledge is profoundly affected by digitalization, as communication-infrastructure and content, production and circulation-has changed. The changed conditions for the circulation of knowledge have an impact on the forms and exercise of power (Couldry 2012). Digitalization can strengthen some forms of power and weaken others, just as it strengthens some forms of knowledge (legitimizing them so they are taken as given) and lessens others.

In this chapter, medical knowledge and its circulation is explored using an example from neuroscientific research, where neuroscientists in focus-group interviews talk about sharing knowledge in different contexts. Sharing knowledge is here identified as a form of knowledge circulation. Sharing knowledge is about spreading information, moving it from one context to another, and the process is permeated with different layers of intentions, interpretations, and meaning-making. As part of a wider circulation, sharing knowledge as a concept highlights the intentional and interactive aspects of the process. I will describe different aspects of sharing knowledge, as they are discussed by researchers in the field of medical knowledge. The medical knowledge in question is the specialized field of neuroscience that is engaged in the search for potential cures for neurodegenerative diseases, so in other words part of a larger paradigm of the medical knowledge frequently examined by the medical humanities.

By exploring views on medical knowledge and its circulation from the perspective of a privileged group-the scientists who are the main actors in producing medical knowledge-the complexity of knowledge circulation can be emphasized. Following James Secord (2004), I consider how and why knowledge circulates, and what happens when it ceases to be the exclusive property of a single individual or group and becomes part of the tacit knowledge held by much wider groups of people. 


\section{Interviews as sharing knowledge}

The empirical material of this chapter consists of qualitative focusgroup interviews with neuroscientists at a university in southern Sweden. The interviews were carried out in a research project about the various framings of the human brain that influence neuroscientific work, and the connection to wider cultural interpretations of the brain. ${ }^{1}$ In the focus-group interviews, participants were asked to describe their work and laboratory procedures. The focus was on their perceptions, opinions, beliefs, and attitudes concerning their work, and sharing knowledge was an aspect that came up in the interviews. The participants were members of two research groups that work with neurons in a laboratory environment, looking for treatments for neurodegenerative diseases. Four focus-group interviews of one to one and a half hours' duration with 3-5 participants apiece were conducted between November 2015 and May 2016. The interviews were transcribed verbatim, but material is presented here with anonymized names and research projects.

Focus-group interviews can themselves be regarded as a form of knowledge-sharing, as they are conversations that produce, share, and circulate knowledge between participants, not just between participants and interviewer. This process is of course influenced by the questions raised and the nature of the interaction between the participants, as there is always the possibility that the participants will direct their attention towards agreement rather than acknowledging differences (Gray 2003). In the present case this will probably have been lessened by the fact that the participants were colleagues who knew one another well.

Another important aspect is that interviews, by dint of being transcribed, become texts. The shared knowledge from the interviews is interpreted, reread, and sorted into patterns by the researcher. A written text can be scrutinized in a way that a verbal conversation cannot. It also vests in the researcher-the interpreter-the power and prerogative of its content (Gunnemark 2011). 


\section{Knowledge circulation and neuroscience}

The concept of circulation can be used as a theoretical perspective. According to Katja Valaskivi and Johanna Sumiala, it is the dynamic structures of circulation that are of interest, and how they connect to power:

The simplest way of thinking about circulation is to say that it is about 'going around' and/or 'passing on' something - whether it is material or immaterial items, goods, artefacts, ideas or beliefs that are being distributed and disseminated.... In this circulatory process, certain ideas, items and actors become more powerful, while others may fade away or change their shape or consistency, thus taking other directions and creating new processes in circulation. (Valaskivi \& Sumiala 2014, 231)

Valaskivi and Sumiala continue by describing three approaches to the topic of circulation. The first is to acknowledge circulation as a non-static, non-linear concept. They underline flexibility in the sense of the direction and tempo of movement. The second approach is to stress circulation as 'an open-ended process, a movement that brings ideas, items and people together' (233). This relates to action, and is explained as 'typically shaped by tensions, contradictions and ambiguities that are represented, reproduced and sustained in the circulation process' (233). Here, power relations shape circulation, but may simultaneously be contested. The third approach is that the materiality of circulation constitutes an essential aspect: circulation involves material objects, which are embedded in ideas, beliefs, ideologies, and emotions.

When such theories of circulation are applied to the circulation of medical knowledge it is easy to see how knowledge moves through academia and societies in a non-linear way (see Latour 1999; Raj 2007). The circulation of knowledge is driven by tensions, contradictions, and ambiguities, where power and resources give some actors better access-and greater credibility - than others. 
The materiality of knowledge circulation is always present, for circulation relies on material objects (from research instruments and printed publications to online publications and information, such as lectures easily accessible through computers and mobile phones), which in turn affect the circulation process.

Another important aspect of medical knowledge circulation is that it is often scientific property. The knowledge is owned. And that ownership has consequences for the circulation process. Stephen Hilgartner (2004) explains that property is not simply things that are owned, but a bundle of rights connected to these entities, with specified limits. To possess property is to be embedded in a fabric of rights and obligations. Property may not always be explicitly recognized by the legal system, as in the example of scientific property, because the relevant property in scientific exchange includes not only formally recognized intellectual property (such as patents, copyrights, and trade secrets), but also what Hilgartner calls 'informal' types of scientific property, such as rights and obligations of the parties to a research collaboration or the authors of a scientific paper. Therefore, property as a concept, legally and morally, is linked to power relations. It is also deeply involved in scientific practices, and, as I discuss in this chapter, in medical knowledge circulation.

Neuroscience is a useful illustration of medical knowledge circulation. Current developments in brain research, with new technological and therapeutic possibilities, have transformed how we understand, manage, and treat people, amounting to an emerging neuro-ontology (Rose \& Abi-Rached 2013; Hansson \& Idvall 2017). The human condition is primarily understood as a self consisting of brainhood rather than personhood (Vidal 2009): people are cerebral subjects. As such, we have access to neuroscientific vocabulary and techniques, especially the colourful images of brain scans, as well as the common-sense notion that being human is exclusively physical and reliant on the brain (Zivkovic 2015). Knowledge of the brain circulates between neuroscience and the public, the media, and politics. It permeates popular culture: media products such as sci-fi series and films 
draw on neuroscience to build imagined, but still vaguely realistic, depictions of what new technology can do to the brain and, by extension, to people. Knowledge circulates back to academia, where neuroscientists are confronted with these (often distorted) representations when meeting patients, watching television, or describing their work to friends or the general public (see Hansson 2017a). The upshot is that the supposed distinction between science and popular culture is constantly challenged by the circulation of knowledge (Alftberg \& Bengtsen 2018).

In the following, I will explore the circulation of medical knowledge and its power dimensions using empirical examples from a neuroscientific setting. I examine the concept of knowledge-sharing in the light of competition, collaboration, and problematic sharing-the themes which emerge when scrutinizing the empirical material for patterns and relevant thematics.

\section{Competition}

When the participating neuroscientists discuss their work in the interviews, it is clear that the aim of each of their research projects is to gain new knowledge. Research is described as a competitive game with projects that need to be innovative but not too risky. According to the participants, any research project has risks-for instance, will it be possible to develop new knowledge or not? If the risks are too great the project risks coming to a dead-end (see Hansson 2017b; Hammarfelt et al. 2016). A project that does not reach any new conclusions is considered a failure. Consequently, risk features in every project, but is connected to power factors such as influence and funding (which projects receive resources, who the influential researchers are, and so on). Academic careers are built on competition-competition for funding, for leadership, for impact, for international reputation (Müller 2014) — which also means there is always a risk of failure.

Medical knowledge, as we have seen, is looked on as property, belonging to one or several researchers, and this too fuels and is 
fuelled by the competitive nature of academia. Competition generates the risk of 'being scooped', when other researchers publish similar findings before you do, or of your idea being stolen. This is described by Daniel and Karen:

Daniel: On the X-project I think it was very clear when we stated that this was a low-risk project based on the techniques, because we had everything set up and available. But it was clearly a highrisk project based on the competition, so we knew very well that it had to be done quickly. The high risk was that we knew that other researchers were about to do the same thing.

Karen: Yes, the risk of being scooped.

Working on a research project and generating new results is a competition against time and other scientists, and there is always the risk that 'your' findings will be pre-empted by someone else. Knowledge is viewed as property that needs to be guarded and kept safe, an approach that hinders the circulation of medical knowledge. It is only once research findings are published that they are free to circulate and be shared. In other words, once medical knowledge is validated and has a clear ownership, sharing is possible. Nevertheless, as the participants explain, the reality is that ideas and knowledge sometimes are scooped, to be used and further developed by other researchers. Circulated, in other words.

The participants see a moral dilemma in doing an experiment that they know others are doing too. They note that, quite apart from the idea of knowledge as property (and property should be respected), on a societal level it could be regarded as a waste of taxpayers' money and, in the long run, reduced public confidence in science. On the other hand, there can be good reasons to do the same experiments, as Karen and Thomas discuss:

Karen: But I think sometimes it's also a problem that people don't want to do the same as other people did because it's already published, and then you, you lack the validation and there's lots 
and lots of data out there that hasn't been validated. And that's a big problem.

Thomas: It depends also on how clever one group versus the other puts that testing. And sometimes one group can be the first, but the other one makes it in a much cleverer way, and in a much more robust way.

Validating knowledge, and doing 'robust' tests to produce it, is a typical description of what is called evidence-based knowledge. Evidence-based knowledge is the process of systematically finding, appraising, and using contemporaneous research findings as the basis for rational decisions (Rosenberg \& Donald 1995; Persson et al. 2017). Originating in medical science, evidence-based knowledge and practice have spread, for instance to social work, and today is the kind of scientific knowledge that commands particularly high confidence in academia and society (see Hansson, Nilsson \& Tiberg and Irwin in this volume). It is considered first-rate knowledge with apparently objective verifications of what reality looks like. ${ }^{2}$ As such, this is the kind of medical knowledge that the participants value, and, considering its high status, knowledge that ought to be circulated and shared.

\section{Collaboration}

While competition in science is discussed by participants, they dwell even more on the question of collaboration. Collaboration is associated with sharing knowledge. The participants reflect on how technological advances have opened the possibility of sharing:

Thomas: In science I consider competition not so useful as collaboration I'd say.

Karen: I guess people share more too.

Emma: Yeah, they share and it's more international.

Anna: It's possible to share. [...] There's access to information and there are possibilities... technical possibilities for sharing. 
Karen: Yeah, it's possible, it's part of technology. But it's also that, it becomes more common that the big labs, when they have a new technique they can... the more software and things... they just put it open source on the Internet, and people are free to use it. Instead of charging money for it or keeping it secret. I mean that's why the CRISPR, for instance this CRISPR technology of editing the human genes, one reason it's become so popular is because the people who developed it they put out software online or on their webpage, which makes it easy for other people to do the same. ${ }^{3}$ To use the technique. So they shared that with everyone. So, I think it's a way of spreading your research to others.

Emma: It feels like in the last ten years that there is much, it gets much better every year. Like, from my point of view for the last ten years that view has changed a lot, you share much more and you've more commercially available tools for your research now than there were eight years ago or ten years ago.

It is not a new insight that technology and digitalization have changed the circulation of knowledge, but it is interesting to see how the participants reflect on the changes that have happened only in the last decade. It has altered their working conditions, but also their view on medical knowledge, and sharing is now 'natural'. Digitalization and the accompanying quantitative, metric-based measurability and the changes it has effected in working conditions in academia have been explored by Ruth Müller (2014), who highlights the experience of being in a highly competitive race that requires a continuously accelerating working pace as well as a strong focus on individual achievement. This relates to the concept of the 'entrepreneurial self' (Bröckling 2005), suggesting continuous self-improvement and flexibility, adapting to market needs (Müller 2014). On the other hand, as the quotes illustrate, digitalization and online availability can also lead to increased transparency and collaboration.

Technology and digitalization are not abstract phenomena, but are dependent on material objects. The materiality of knowledge 
circulation - the physical objects needed to produce and share it-affects the circulation (how, when, and how fast), and partially erodes the view of knowledge as property. In current research, sharing and collaboration could be more relevant than competition and keeping things to yourself (Laudel 2001; Müller 2012). Still, the reason for sharing should not be perceived as merely altruistic; sharing knowledge is a strategy for a successful career:

Karen: I think today it [sharing] is viewed as a strategy for success. Whereas maybe previously it's been more like keeping secret. But today it's viewed as a route to success of actually sharing because that means that more people will cite your work and... [...] It increases their impact.

Anna: Because now it is possible to monitor the number of times that published works are cited...

The materiality of knowledge circulation has changed the conditions of scientific publication and publication rates. This in turn seemingly influences the way success is being defined: it is to be published and, even more importantly, to be cited (Hammarfelt 2017). Sharing may promote collaboration, but paradoxically, because of its connection to a successful career, it also promotes competition (see Müller 2014). According to the participants, the greater circulation of medical knowledge is a desired process. Nevertheless, there is also the underlying notion of 'the entrepreneurial self' (Bröckling 2005), where sharing knowledge in publications and the number of citations is a career strategy.

\section{Problematic sharing}

The participants also discussed how knowledge is shared between patients. For instance, patients may share (often positive) experiences of treatments and information they have acquired. This information is part of a medical circulation of knowledge outside academia, often using social media. Online social networking has 
changed how people communicate with one another, and how they identify relevant information and share it (Eysenbach 2008). One example is communication between people based on their medical diagnoses, creating patient forums where they can express and compare their experiences (see Hagen 2012). In the social media, patients' experiences may become ostensibly medical knowledge:

Anna: Of course there's always people who feel that they are helped by this, then they do... advertise you know that 'I went there and it was great or I did that', on Facebook, which is a new way of communicating all sorts of things.

Karen: It's easier to read Facebook than a scientific article. Anna: Yeah. And people hear what they want to hear. So if they want to feel better, they hear someone who felt better and they want to do the same thing. They don't want to hear the arguments why it wouldn't feel better.

Thomas: And some of them actually cite scientific papers.

Karen: Oh yes, really bad examples.

Thomas: Twisted! They select a particular phrase and then they go bananas and just claim that... [...] and there's no relationship.

This form of knowledge-sharing is regarded as problematic by the participants, since, according to them, the patients risk getting the information wrong or the wrong kind of medical knowledge. Even though there could be so-called expert patients with considerable knowledge about their diseases and new treatments, the participants feel that this only can instil false hopes of treatments or cures (for patient involvement, see Idvall in this volume). ${ }^{4}$

There is a global circulation of medical knowledge, which the sociologist and medical anthropologist Mary-Jo DelVecchio Good (2010) calls the medical imaginary. The medical imaginary-the affective and imaginative dimensions of biomedicine and biotechnology that embrace clinics, patients, and publics - circulates through professional and popular culture. Alternative stories, misuses, and failures of medicine's power and possibilities are also part of the 
medical imaginary (failures, fraud, discouragement, and greed); yet, broadly speaking it is an optimistic story of hope and the possibilities of medical science (Brown \& Michael 2003). When patients share, access, and use this medical knowledge, it may be perceived as problematic though. According to the participants, the patients' sharing of information has its ethical risks and misunderstandings of what medical science can and cannot do. But there also seems to be an element of losing control. The scientists do not have control over the information that circulates in the social media. Again, referring to the idea of knowledge as a property, the implicit view is that medical knowledge belongs to science and the scientists, not the patients. Digitalization, such as social media, makes it more difficult to hold on to this distinction. However, the solution to the perceived lack of control is not to hinder information; rather it is to increase the distribution of correct medical knowledge (for example, by using social media), and to do so through being more active and engaged as a researcher. As one explains:

Anna: What you can do is things like you can be active and present your research to the community. If you show alternatives, if you try to reach as many people as possible and you try to show that we are making progress at the universities, at the established research institutes, and then try to inform... Because I think that often they feel that nothing is going to happen at the universities for ten years, so I can't sit around and wait for that, I'll go elsewhere. If you try to describe the progress and things better...

Were people and patients to understand the ongoing knowledge production and progress in established research, they would not be tempted to 'go elsewhere' as Anna put it. According to the participants, patients desperate for new treatments are open to exploitation by commercial interests. Nancy Scheper-Hughes (2003) explains how advanced medical procedures and biotechnologies are now becoming part of new markets. The field of organ transplant is the most distinctive outcome of the combination of capital and medical 
technology in a transnational space, but there are also treatments that involve other body parts: tissues, cells, and reproductive and genetic material of others (Lundin 2012, 2015). When the participants discuss treatment 'elsewhere', they highlight how private clinics may offer medical treatments that are not tested and not safe for humans:

Karen: There's a very big clinic in Ukraine, which is probably one of the biggest.

Emma: Yeah, it was on the news today that they had transplanted a retina. That was not supposed to be in experiments, in pre-clinical research. But they had transplanted them into patients.

Another example is the use of stem cell transplants, where the participants draw a distinct line between their own research and clinical trials, and false treatments that are considered experiments with no scientific (for which read evidence-based) basis:

Andrew: I think it's crazy that those places where you can do those stem cell transplants, that they even exist and that they're allowed to exist... fooling patients into believing they can be cured. That's really doing experiments on humans.

Karen: There's no scientific background.

Thomas: They will not say cure but will help this and that, and that's been going on in Europe and in the States because there is no regulation for that. You don't have to prove anything. You just have to... I think, I only think you need to show that, don't die from it, that's it. Otherwise, if it makes an improvement, no one cares.

Treatments that are not evidence-based or tested in clinical trials, with no requirement of proof, are not regarded as proper science. For the participants, going straight from findings in the lab to treatment, leaving out the trial stage, poses great risks to patients, and distinguishes this as a highly unethical and non-scientific procedure. 
The circulation of medical knowledge is perceived as a misuse in cases like this. Also, commercial interests are contrasted to what science is and should be by definition, which becomes clear when Anna comments that the clinics' intention is not to cure people but to make money:

Anna: It's just charging people money. It's not for advancing science, it's for making money... Because if they collected data from it, it would perhaps be somewhat helpful.

According to Anna, these experimental treatments might be useful if they were to collect the data involved, as the clinics would thus share their knowledge and contribute to the knowledge circulating about stem cell research. This contradicts the idea that there is no scientific basis to this; rather, if the clinics were to follow correct scientific procedure and produce evidence-based knowledge they could contribute. This ambivalence recurs in the discussion of these kinds of clinics. Participants agree, for example, that staff at these clinics are 'technically' researchers, because they have doctorates. As Anna says, 'Well I'm sure that they employ people with PhDs and MDs. And then they're technically researchers.' As such, they may even be encountered at scientific conferences:

Karen: I met one of them [at a conference]. She came up to me and said how do you do that transplantation, do you just inject the cells in the blood? After talking to her it was really, really clear that they have... they don't know anything, they have no clue. They have no clue what they're doing.

Commercial clinic staff are not regarded as proper scientists and therefore sharing knowledge with them is impossible. Even though the clinic may have legal permission to obtain human embryos and have consent from the patients, the ethical aspects are too problematic. Karen says that she spoke her mind to the woman: they should not be doing anything like this at the clinic, and it could be a 
huge danger to the patients. Discussing the topic further, it appears that the physical risk to patients may not always be severe (even though it is never completely risk-free). It depends, for example, on whether the treatment involves injections of stem cells into the blood (injecting systemically) or into the brain:

Anna: It's a lot cheaper to inject systemically than into the brain, it's a lot easier so... The risk is much lower than if you were to inject into the brain.

Karen: Yeah. The most likely scenario is nothing will happen.

Accordingly, the physical risks to patients are often low (the patients' emotional turmoil, cast between despair and hope, and their financial investment in the treatment are other risks). Still, sharing knowledge in the situation described above is unimaginable, however low the risk to patients. Medical knowledge circulation has its limits, and the actors who produce knowledge can try to make it inaccessible for ethical and professional reasons.

\section{The frictions of sharing knowledge}

This chapter has explored the circulation of medical knowledge in a neuroscientific setting. It has illustrated situations where knowledge-sharing is considered by the participants to be useful and valuable, and situations when it is regarded as disadvantageous or highly problematic for ethical reasons.

The participants connect sharing medical knowledge to both competition and collaboration as well as a career strategy. There is an underlying aspect of power and influence: whose findings are spread and accepted, and how fast can it be done (in order not to get scooped)? The circulation of knowledge is affected by digitalization, which has changed the conditions of scientific publication and publication rates, and, by extension, success. It also creates tensions and contradictions. Sharing is both natural and expected, but you simultaneously risk 'your' knowledge being poached by 
someone else. Parallel to that, medical knowledge has to warrant the label of evidence-based if both academia and society are to hold it in high confidence.

Permeating the empirical examples is the idea that medical knowledge has ownership. It can be shared but it is always owned by someone, or by some more than others, and is part of power relations. The idea of property can be linked to the commodification of knowledge. ${ }^{5}$ Medical knowledge as a commodity means that it should be valued by, and of service to, the market. It ought to be measured and controlled, just like any other resource. But, since the circulation of knowledge is non-static, non-linear, and flexible in its sense of direction and speed of movement, it defies control and produces what I have called problematic sharing. When sharing knowledge, it can rarely stay the exclusive property of a single individual or group. Rather, it becomes part of the accepted understanding of much wider groups of people, which may lead to criticism and disapproval from the group who see it as their property. Power relations are contested, as seen here in the use of digital media. According to the empirical examples, one strategy when knowledge (the property) is circulated and used in problematic, misinformed ways (as by patients) is to share information increasingly, and make sure it is the correct kind of medical knowledge that circulates (evidence-based). As one of the participants said, contributing accurate knowledge could bring patients to realize that treatments at commercial clinics are not an alternative. Another strategy is not to share knowledge at all, as in the example of encountering representatives of the commercial clinics at a scientific conference. The ethical risks involved for patients who are exploited by commercial clinics that offer non-evidence-based treatments are of course real, and should not be overlooked or downplayed. Nonetheless, ethical risks may well be used as arguments in order to guard and preserve the ownership of scientific knowledge, withholding power and privileged status.

To conclude, sharing medical knowledge is a process of intention 
and interaction, competition and collaboration. The concept of knowledge-sharing helps highlight how knowledge circulation is affected by digitalization, which changes scientific working conditions and sometimes makes sharing problematic. It reveals the underlying idea that knowledge is exclusive property, and the frictions that occur when this idea is challenged.

\section{Notes}

1 The project was financed by the Basal Ganglia Disorders Linnaeus Consortium and named 'What makes us human? Cultural perspectives on framings of the brain in neurological research'. The focus-group interviews were conducted by Kristofer Hansson, Markus Idvall, and Ellen Suneson.

2 At the same time, evidence-based knowledge is under fire from scientific disciplines founded on other epistemological grounds. The philosopher Maya Goldenberg (2006) points out that the seemingly unproblematic nature of evidence-based knowledge may be contested by emphasizing science as a social system of knowledge production. Evidence-based knowledge does not increase objectivity; rather it obscures the subjective elements that inevitably are part of all forms of human inquiry.

3 CRISPR is a family of DNA sequences in bacteria and archaea. It is a kind of molecular machinery designed to destroy intrusive DNA sequences, for example from viruses. It is used as a technology to affect DNA segments in the cell nucleus.

4 The expert patient (spetspatient in Swedish) is a patient who uses the Internet as an important source of disease-specific knowledge, and joins forces with fellow patients in patient organisations and similar. Riggare et al. 2017 describes this as an ongoing change for chronic conditions in healthcare: a shift from a model where healthcare professionals are experts and the patients are passive recipients of care to a model where patients are active participants who have the possibility to be experts in managing their own disease and situation. This indicates a reliance on patients' self-management and patient education, which can be problematized with the concept of self-care (see, for example, Hansson elsewhere in this volume; Alftberg \& Hansson 2012).

5 This has long been a subject of discussion, for example Gibbons \& Wittrock 1985; Gibbons et al. 1994; McKelvey \& Holmén 2009; Benner \& Widmalm 2011.

\section{References}

Alftberg, Åsa \& Kristofer Hansson (2012), 'Introduction: Self-care translated into practice', Culture Unbound: Journal of Current Cultural Research, 4, 415-24.

- - \& Peter Bengtsen (2018), 'The sci-fi brain: Narratives in neuroscience and popular culture, Culture Unbound: Journal of Current Cultural Research, 10(1), 11-30.

Benner, Mats \& Sven Widmalm (2011), Kunskap (Malmö: Liber).

Bröckling, Ulrich (2005), 'Gendering the enterprising self', Distinktion: Scandinavian Journal of Social Theory, 6(2), 7-25. 
Brown, Nik \& Mike Michael (2003), 'A sociology of expectations: Retrospecting, prospects and prospecting retrospects', Technology analysis \& strategic management, 15(1), 3-18.

Couldry, Nick (2012), Media, society, world: Social theory and digital media practice (Cambridge: Polity).

DelVecchio Good, Mary-Jo (2010), 'The medical imaginary and the biotechnical embrace: Subjective experiences of clinical scientists and patients', in, Byron J. Good, Michael M. J. Fischer, Sarah S. Willen \& Mary-Jo DelVecchio Good (eds.), A reader in medical anthropology: Theoretical trajectories, emergent realities (Oxford: Wiley-Blackwell).

Eysenbach, Gunther (2008), 'Medicine 2.0: Social networking, collaboration, participation, apomediation, and openness', Journal of Medical Internet Research, 10(3), e22.

Gibbons, Michael \& Björn Wittrock (1985) (eds.), Science as a commodity: Threats to the open community of scholars (London: Longman).

Gibbons, Michael, Camille Limoges, Helga Nowotny, Simon Schwartzman, Peter Scott \& Martin Trow (1994), The new production of knowledge (London: Sage).

Goldenberg, Maya J. (2006), 'On evidence and evidence-based medicine: Lessons from the philosophy of science' Social Science \& Medicine, 62, 2621-32.

Gray, Ann (2003), Research practice for cultural studies: Ethnographic methods and lived cultures (London: Sage).

Gunnemark, Kerstin (2011) (ed.), Etnografiska hålplatser: Om metodprocesser och reflexivitet (Lund: Studentlitteratur).

Hagen, Niclas (2012), 'A molecular body in a digital society', in Max Liljefors, Susanne Lundin \& Andrea Wiszmeg (eds.), The atomized body (Lund: Nordic Academic Press).

Hammarfelt, Björn, Sarah de Rijcke \& Alexander D. Rushforth (2016), 'Quantified academic selves: The gamification of research through social networking services', Information Research, 21(2).

- - (2017), 'Recognition and reward in the academy', Aslib Journal of Information Management, 69(5), 607-623.

Hansson, Kristofer \& Markus Idvall (2017) (eds.), Interpreting the brain in society: Cultural reflections on neuroscientific practices (Lund: Arkiv Förlag).

- - (2017a) 'Mixed emotions in the laboratory: When scientific knowledge confronts everyday knowledge', in Hansson \& Idvall 2017.

- - (2017b), 'Det mätbara arbetslivet i laboratoriet', Kulturella Perspektiv, 3-4, 8-17.

Hilgartner, Stephen (2004), 'Mapping systems and moral order: Constituting property in genome laboratories', in Sheila Jasanoff (ed.), States of knowledge: The co-production of science and social order (New York: Routledge).

Jasanoff, Sheila (2004), 'Ordering knowledge, ordering society', in ead. (ed.), States of knowledge: The co-production of science and social order (New York: Routledge).

Latour, Bruno (1999), Pandora's hope: Chapters on the reality of science studies (Cambridge, MA: Harvard University Press).

Laudel, Grit (2001), 'Collaboration, creativity and rewards: Why and how scientists collaborate', International Journal of Technology Management, 22(7-8), 762-81.

Lundin, Susanne (2012), 'Moral accounting: Ethics and praxis in biomedical research', in Max Liljefors, Susanne Lundin \& Andrea Wiszmeg (eds.), The atomized body (Lund: Nordic Academic Press).

- - (2015), Organs for sale: An ethnographic examination of the international organ trade (London: Palgrave Macmillan).

Markovits, Claude, Jacques Pouchepadass \& Sanjay Subrahmanyam (2006) (eds.), Society and circulation: Mobile people and itinerant cultures in South Asia, 1750-1950 (London: Anthem). 
McKelvey, Maureen \& Magnus Holmén (2009) (eds.), Learning to compete in European universities: From social institution to knowledge business (Cheltenham: Edward Elgar).

Müller, Ruth (2012), 'Collaborating in life science research groups: The question of authorship', Higher education policy, 25(3), 289-311.

- - (2014), 'Racing for what? Anticipation and acceleration in the work and career practices of academic life science postdocs', Forum: Qualitative Social Research, 15(3).

Östling, Johan, David Larsson Heidenblad, Erling Sandmo, Anna Nilsson Hammar \& Kari H. Nordberg (2018), 'The history of knowledge and the circulation of knowledge: An introduction', in eaed. (eds.), Circulation of knowledge: Explorations in the history of knowledge (Lund: Nordic Academic Press).

Persson, Johannes, Niklas Vareman, Annika Wallin, Lena Wahlberg \& Nils-Eric Sahlin (2019), 'Science and proven experience: A Swedish variety of evidence-based medicine and a way to better risk analysis?', Journal of Risk Research, 22(7), 833-843.

Raj, Kapil (2007), Relocating modern science: Circulation and the construction of knowledge in South Asia and Europe, 1650-1900 (Houndmills: Palgrave Macmillan).

Riggare, Sara, Pär J. Höglund, Helena Hvitfeldt Forsberg, Elena Eftimovska, Per Svenningsson \& Maria Hägglund (2017), 'Patients are doing it for themselves: A survey on disease-specific knowledge acquisition among people with Parkinson's disease in Sweden', Health Informatics Journal, 1-15.

Rose, Nikolas \& Joelle M. Abi-Rached (2013), Neuro: The new brain sciences and the management of the mind (Princeton: PUP).

Rosenberg, William \& Anna Donald (1995), 'Evidence based medicine: An approach to clinical problem-solving', $B M J, 310,1122-6$.

Scheper-Hughes, Nancy (2003), 'Rotten trade: Millennial capitalism, human values and global justice in organs trafficking', Journal of Human Rights, 2(2), 197-226.

Valaskivi, Katja \& Johanna Sumiala (2014), 'Circulating social imaginaries: Theoretical and methodological reflections', European Journal of Cultural Studies, 17(3), 229-43.

Vidal, Fernando (2009), 'Brainhood, anthropological figure of modernity', History of the Human Sciences, 22(1), 5-36.

Zivkovic, Marko (2015), 'Brain culture: Neuroscience and popular media', Interdisciplinary Science Review, 40(4), 409-417. 